\title{
THEORETICAL RESEARCH ON THE MULTI-CHANNEL REACTION MECHANISM AND KINETICS OF HNCS WITH OH-
}

\author{
Li-Jie Hou,*, Bo-Wan Wua , Yan-Xia Han ${ }^{\mathrm{a}}$, Chao Konga and Li-Guo Gao ${ }^{\mathrm{b}}$ \\ ${ }^{a}$ College of Chemistry \& Chemical Engineering, Longdong University, 745000, Qingyang, China \\ ${ }^{\mathrm{b}} \mathrm{S}$ chool of Chemistry \& Chemical Engineering, Yulin University, 719000, Yulin, China
}

Recebido em 07/03/2017; aceito em 26/06/2017; publicado na web em 15/08/2017

\begin{abstract}
We presented a theoretical study on the detailed reaction mechanism and kinetics of the HNCS molecule with the $\mathrm{OH}^{-}$. The barrierless minimum energy path and the most favorable entrance channel have been determined by study the thermodynamic and kinetic characters of the channel with low energy barrier. The B3LYP/6-311++G** method was employed for all the geometrical optimizations and a multi-level extrapolation method based on the G3 energies was employed for further energy refinements. In addition, the analysis of the combining interaction between hydroxide ion and HNCS was performed by natural bond orbitals (NBO) analysis. The calculation results indicated that the reaction of $\mathrm{OH}^{-}$with $\mathrm{HNCS}$ had four channels, and the channel of $\mathrm{H}$-atom in HNCS direct extraction to $\mathrm{OH}^{-}\left(\mathrm{OH}^{-}+\mathrm{HNCS} \rightarrow \mathrm{IM} 1 \rightarrow \mathrm{TS} 3 \rightarrow \mathrm{IM} 4 \rightarrow \mathrm{P} 2\left(\mathrm{SCN}^{-}+\mathrm{H}_{2} \mathrm{O}\right)\right)$ in singlet state was the main channel with the low potential energy and high equilibrium constant and reaction rate constant. $\mathrm{SCN}^{-}$and $\mathrm{H}_{2} \mathrm{O}$ were main products.
\end{abstract}

Keywords: hydroxide ion; isothiocyanic acid; mechanism; equilibrium constant

\section{INTRODUCTION}

The problem of the severe air pollution in developing countries has caused wide public concern over the recent years, heavy power plant smoke and car emissions, mainly in the form of sulfate, organic, nitric acid and particles, have always been a threat to the global public health. In the meanwhile, as important intermediates of sulfur-containing fuel combustion process, HNCS and its derived free radical NCS can participate in the process of removal the toxic $\mathrm{NO}_{4}$ compounds from rapid combustion exhaust gas too. ${ }^{1-6}$ Due to its important role, the theoretical study on the reaction mechanism of HNCS with small molecules by quantum chemistry calculation also become the focus of the chemical workers' research. ${ }^{7-19}$

Because its oxidation ability is very strong, hydroxide ion $\left(\mathrm{OH}^{-}\right)$ is one of the key intermediates in the interstellar environment and a large number of combustion reaction, not only represents a very important role that $\mathrm{OH}^{-}$can oxidized volatile organic compounds in the troposphere gas, ${ }^{20}$ but also plays an important role in atmospheric chemistry where it is the primary process responsible for removal of the $\mathrm{H}_{2} \mathrm{CO}$ pollutant. ${ }^{21-25}$ Molecular anions play an important role in the chemistry of the interstellar medium, of carbon stars , and the Earth's ionosphere. One such species is the hydroxide ion. Madura and Jorgensen applied ab initio calculation to discuss the addition of hydroxyl anion to the aldehydic carbon atom. ${ }^{26}$ Herein, we used the density functional theory (DFT) to explore the reaction mechanism of $\mathrm{OH}^{-}$with $\mathrm{HNCS}$, We hope our work might provide theoretical guidance to control $\mathrm{NO}_{\mathrm{x}}$ substance-related air pollution effectively.

\section{CALCULATION METHODS}

All calculations were performed with the Gaussian 03 package. ${ }^{27}$ The geometries of reactants, intermediates, transition states and products were optimized at the DFT-B3LYP/6-311++G** level. ${ }^{28-31}$ The harmonic vibration frequencies obtained at the corresponding level were used to characterize the stationary points and first-order saddle points. The intrinsic reaction coordinate (IRC) calculation

*e-mail: 200hlj@163.com was used to track minimum energy paths from transition structures to stationary points. To obtain more precise energy results, stationary point energies were calculated at the G3 level. The thermodynamic and kinetic characters of the channel with low energy barrier were calculated by the statistical thermodynamics and Eyring transition state theory with Winger correction at different temperatures.

\section{RESULTS AND DISCUSSION}

\section{Channels of singlet state $\mathrm{OH}^{-}$with $\mathrm{HNCS}$}

Calculations showed the reaction of singlet state $\mathrm{OH}^{-}$with HNCS had four channels. NBO calculation results indicated that precursor complex IM1 formed when the lone electron pair of O-atom in $\mathrm{OH}^{-}$interacted with $\sigma^{*}(\mathrm{C}-\mathrm{S})$ and $\sigma^{*}(\mathrm{~N}-\mathrm{H})$ in HNCS, respectively. ${ }^{32}$ The abstraction reactions of S-atom and $\mathrm{H}$-atom in HNCS transfer occurred by using IM1 as starting intermediate. The lone electron pair of $\mathrm{O}$-atom in $\mathrm{OH}^{-}$and $\mathrm{N}$-atom in $\mathrm{HNCS}$ interacted with the $\sigma^{*}(\mathrm{C}-\mathrm{S})$ and $\sigma^{*}(\mathrm{C}-\mathrm{N})$ of HNCS to form IM1 intermediate. This interaction leaded to the reduction of $\mathrm{O}-\mathrm{C}$ and $\mathrm{N}-\mathrm{H}$ bond strength, and prompted $\mathrm{H}$-atom in $\mathrm{OH}^{-}$transfer. Therefore, the reaction of singlet state $\mathrm{OH}^{-}$ with HNCS was complicated and multichannel.

\section{H1-atom in HNCS transfer to $\mathrm{OH}^{-}$channel}

HNCS collided with the singlet state $\mathrm{OH}^{-}$to form an intermediate IM1, and then IM1 generated intermediate IM4 via transition state TS3. After that, IM4 dissociated to generate product $\mathrm{P} 2\left(\mathrm{SCN}+\mathrm{H}_{2} \mathrm{O}\right)$. As shown in Figure 1, the bond length of H1-N in HNCS increased from IM1 $(0.1022 \mathrm{~nm})$ to TS3 $(0.1207 \mathrm{~nm})$ to IM4 $(0.2078 \mathrm{~nm})$ and the bond length of H1-O was gradually decreased from $0.2062 \mathrm{~nm}$ (IM1) to $0.1223 \mathrm{~nm}$ (TS3). This result indicated that H1-N bond cleaved and $\mathrm{H} 1-\mathrm{O}$ bond formed gradually in this process. The $\mathrm{H}$-atom of $\mathrm{HNCO}$ directly bonded with $\mathrm{O}$-atom in $\mathrm{OH}^{-}$, and the reaction of $\mathrm{H} 1$-atom in $\mathrm{HNCS}$ transfer to $\mathrm{OH}^{-}$performed. As shown in Figure 2, the energy barrier of the reaction step from IM1 to IM4 via TS3 was $285.3 \mathrm{~kJ} \mathrm{~mol}^{-1}$, which was lower and advantageous in kinetics. The whole reaction was exothermic, and the heat generated in reaction was $616.0 \mathrm{~kJ} \mathrm{~mol}^{-1}$, which was thermodynamically favorable to 
this reaction process. As could be see from Table 1, the rate and equilibrium constants of reaction were large at the temperature range of 700 to $2000 \mathrm{~K}$. Therefore, the channel of H1-atom in HNCS transfer to $\mathrm{OH}^{-}$was the major reaction channel.

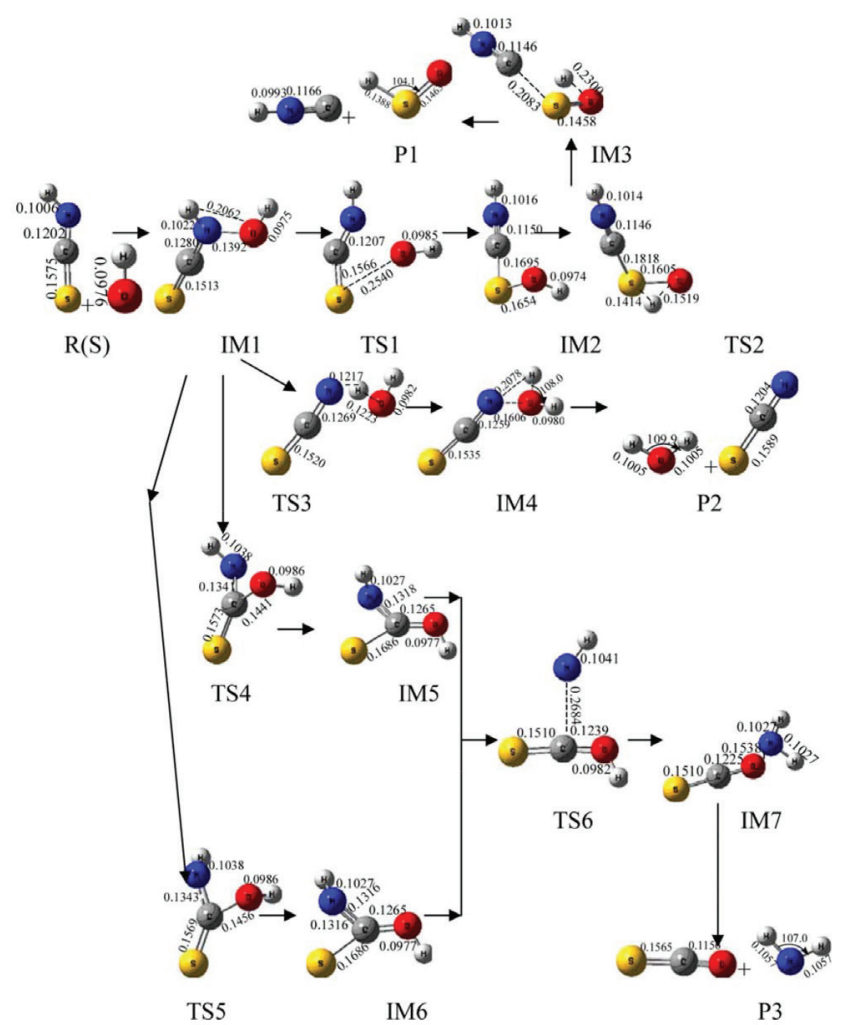

Figure 1. Optimized geometries of various species in reaction in singlet state (bond lengths in $\mathrm{nm}$ and bond angles in degree)

\section{S-atom abstraction channel}

In Figure 1, the $\mathrm{S}$ atom combined with $\mathrm{O}$ atom of IM1 to form a stable intermediate IM2 through transition state TS1. In IM2, $\sigma(\mathrm{C}-\mathrm{S})$ interacted with $\sigma^{*}(\mathrm{C}-\mathrm{N})$ and the lone electrons pairs of $\mathrm{S}$-atom and $\mathrm{N}$-atom in $\mathrm{HNCS}$, leading to the weakening of $\mathrm{C}-\mathrm{S}$ bond. From IM1 to IM2, the C-S bond length increased to 0.1566 from $0.1513 \mathrm{~nm}$, the $\mathrm{O}-\mathrm{S}$ bond length decreased to $0.1654 \mathrm{~nm}$ in IM2 from $0.2540 \mathrm{~nm}$ in TS1, which indicated that the strength of C-S bond gradually weakened and the strength of $\mathrm{O}-\mathrm{S}$ bond gradually enhanced. Subsequently, IM2 generated IM3 through transition state $\mathrm{TS} 2$, and then IM3 dissociated to generate product $\mathrm{P} 1\left(\mathrm{HSO}^{-}+\mathrm{CNH}\right)$, and $\mathrm{S}$-atom abstraction was completed. The energy barrier was $340.4 \mathrm{~kJ} \mathrm{~mol}^{-1}$ from IM1 to IM2, and that of the reaction step from IM3 to IM2 was $317.3 \mathrm{~kJ} \mathrm{~mol}^{-1}$. The whole reaction was exothermic reaction with $518.3 \mathrm{~kJ} \mathrm{~mol}^{-1}$ of heat liberated. Moreover, the reaction equilibrium and rate constants were small in the temperature range from 100 to $1600 \mathrm{~K}$. Therefore, this reaction process was a minor reaction channel.

\section{H2-atom in $\mathrm{OH}^{-}$transfer to $\mathrm{NH}$ channel}

IM1 through TS4 and TS5 form intermediate IM5 and IM6 with the reaction energy barrier of 271.3 and $223.2 \mathrm{~kJ}$ mol-1 respectively. In this step, the length of $\mathrm{C}-\mathrm{O}$ bond changed from $0.1441 \mathrm{~nm}$ in TS4 and $0.1456 \mathrm{~nm}$ in TS5 to $0.0977 \mathrm{~nm}$ in IM6(Figure 1)which indicated that $\mathrm{C}-\mathrm{O}$ bond gradually enhanced until their formation. It is worth mentioning that IM5 and IM6 is cis-trans isomer. From IM5 and IM6 to TS6, the lengths of C-N bond increased to 0.2684 $\mathrm{nm}$ from $0.1265 \mathrm{~nm}$. These results indicated that $\mathrm{N}-\mathrm{C}$ bond gradually

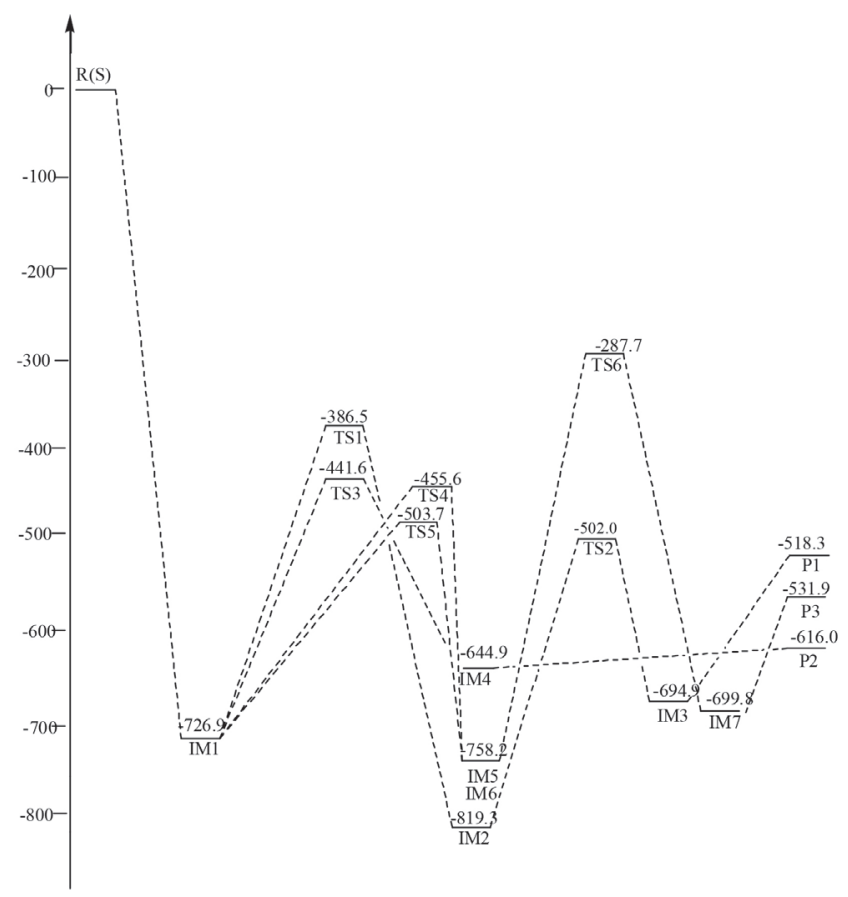

Figure 2. Schematic map of energy levels in singlet state (relative energies in $\mathrm{kJ} \mathrm{mol}^{-1}$ )

weakened and fracture until IM7 generated in this reaction process. Afterwards, IM7 dissociated to product $\mathrm{P} 3\left(\mathrm{NH}_{2}{ }^{-}+\mathrm{COS}\right)$. The whole reaction was exothermic with the total liberated heat of $531.9 \mathrm{~kJ} \mathrm{~mol}^{-1}$, and the energy barrier from IM5 and IM6 to IM7 through TS6 was $470.5 \mathrm{~kJ} \mathrm{~mol}^{-1}$ which was higher than that of the major reaction channel. The reaction rate constants of $\mathrm{H} 2$-atom in $\mathrm{OH}^{-}$transfer to $\mathrm{NH}$ channel was large, but the equilibrium constants were small at the temperature range from 100 to $1200 \mathrm{~K}$. Therefore, these two channels were not the major reaction pathway.

\section{Channels of triplet state $\mathrm{OH}^{-}$with $\mathrm{HNCS}$}

Calculation results indicated that triplet state $\mathrm{OH}^{-}$could also react with HNCS. This reaction had two channels including absorption of ${ }^{3} \mathrm{OH}^{-}$and $\mathrm{H} 1$-atom in $\mathrm{HNCS}$ transfer to $\mathrm{OH}^{-}$channel. The NBO results showed the lone electron pair of $\mathrm{O}$-atom in ${ }^{3} \mathrm{OH}$ anions interacted with $\sigma^{*}(\mathrm{C}-\mathrm{N})$ of HNCS in ${ }^{3} \mathrm{IM} 1$ which was used as the precursor complex to accomplish absorption $\mathrm{OH}^{-}$reaction. ${ }^{3} \mathrm{IM} 2$ formed due to the interaction between $\sigma^{*}(\mathrm{~N}-\mathrm{H})$ of HNCS with the lone electron pair of $\mathrm{O}$-atom in ${ }^{3} \mathrm{OH}$, which leaded to the weakening of $\mathrm{N}-\mathrm{H}$ bond and the occurring of $\mathrm{H1}$-atom transfer to $\mathrm{OH}^{-}$reaction.

\section{$\mathrm{OH}^{-}$abstraction channel}

The lone electron pair of $\mathrm{O}$-atom in ${ }^{3} \mathrm{OH}^{-}$interacted with $\sigma^{*}(\mathrm{C}-\mathrm{N})$ of HNCS to form ${ }^{3} \mathrm{IM} 1$, which could generated product ${ }^{3} \mathrm{P} 1\left({ }^{3} \mathrm{HNCSOH}\right)$ through ${ }^{3} \mathrm{TS} 1$. As shown in Figure 3, the length of $\mathrm{C}-\mathrm{O}$ bond decreased to $0.1300 \mathrm{~nm}\left({ }^{3} \mathrm{IM} 1\right)$ from $0.1210 \mathrm{~nm}\left({ }^{3} \mathrm{P} 1\right)$. In this process, the strength of $\mathrm{C}-\mathrm{O}$ bond formed gradually. Finally, $\mathrm{OH}^{-}$combined with $\mathrm{C}$, and the direct extraction $\mathrm{OH}^{-}$reaction was accomplished. As shown in Figure 4, the energy barrier was $144.8 \mathrm{~kJ} \mathrm{~mol}^{-1}$ in the reaction step from ${ }^{3} \mathrm{IM} 1$ to ${ }^{3} \mathrm{P} 1$ through ${ }^{3} \mathrm{TS} 1$. The whole reaction released $446.3 \mathrm{~kJ} \mathrm{~mol}^{-1}$.

\section{H1-atom in HNCS transfer to $\mathrm{OH}^{-}$channel}

In Figure $4,{ }^{3} \mathrm{IM} 2$ formed ${ }^{3} \mathrm{IM} 3$ through transition state ${ }^{3} \mathrm{TS} 2$ with the energy barrier of $308.5 \mathrm{~kJ} \mathrm{~mol}^{-1}$, and the length of $\mathrm{H} 1-\mathrm{N}$ bond increased to $0.1257 \mathrm{~nm}\left({ }^{3} \mathrm{TS} 2\right)$ from $0.1532 \mathrm{~nm}\left({ }^{3} \mathrm{IM} 2\right)$. The length 
Table 1. In temperature range of from 100 to $2000 \mathrm{~K}$, the equilibrium constant (K) and rate constant (k(s)) of the reaction in singlet state with low energy barrier at $1.0 \mathrm{~atm}$

\begin{tabular}{|c|c|c|c|c|c|c|c|c|}
\hline $\mathrm{T} / K$ & $\mathrm{IM} 1 \rightarrow \mathrm{P} 1$ & $\mathrm{IM} 1 \rightarrow \mathrm{P} 2$ & $\mathrm{IM} 1 \rightarrow \mathrm{P} 3$ & $\mathrm{IM} 1 \rightarrow \mathrm{TS} 3 \rightarrow \mathrm{IM} 4$ & $\mathrm{IM} 1 \rightarrow \mathrm{TS} 4 \rightarrow \mathrm{IM} 5$ & $\mathrm{IM} 1 \rightarrow \mathrm{TS} 5 \rightarrow \mathrm{IM} 5$ & $\mathrm{IM} 5 \rightarrow \mathrm{TS} 6 \rightarrow \mathrm{IM} 7$ & $\mathrm{IM} 6 \rightarrow \mathrm{TS} 6 \rightarrow \mathrm{IM} 7$ \\
\hline 1/N & $\mathrm{K}$ & $\mathrm{K}$ & $\mathrm{K}$ & $\mathrm{k} / \mathrm{s}^{-1}$ & $\mathrm{k} / \mathrm{s}^{-1}$ & $\mathrm{k} / \mathrm{s}^{-1}$ & $\mathrm{k} / \mathrm{s}^{-1}$ & $\mathrm{k} / \mathrm{s}^{-1}$ \\
\hline 100 & $3.92 \times 10^{-132}$ & $8.68 \times 10^{131}$ & $5.68 \times 10^{341}$ & $4.30 \times 10^{-87}$ & $2.30 \times 10^{-92}$ & $4.65 \times 10^{-101}$ & $6.49 \times 10^{--204}$ & $6.41 \times 10^{-204}$ \\
\hline 200 & $3.89 \times 10^{-63}$ & $1.78 \times 10^{62}$ & $8.57 \times 10^{240}$ & $3.09 \times 10^{-37}$ & $3.11 \times 10^{-40}$ & $1.40 \times 10^{-44}$ & $3.21 \times 10^{-95}$ & $3.19 \times 10^{-95}$ \\
\hline 300 & $5.56 \times 10^{-40}$ & $1.61 \times 10^{39}$ & $1.23 \times 10^{163}$ & $1.21 \times 10^{-20}$ & $7.56 \times 10^{-23}$ & $9.56 \times 10^{-26}$ & $1.02 \times 10^{-58}$ & $1.01 \times 10^{-58}$ \\
\hline 400 & $2.28 \times 10^{-28}$ & $5.46 \times 10^{28}$ & $1.59 \times 10^{124}$ & $2.44 \times 10^{-12}$ & $3.90 \times 10^{-14}$ & $2.63 \times 10^{-16}$ & $2.32 \times 10^{-40}$ & $2.31 \times 10^{-40}$ \\
\hline 500 & $2.14 \times 10^{-21}$ & $4.70 \times 10^{21}$ & $7.44 \times 10^{100}$ & $2.42 \times 10^{-7}$ & $6.86 \times 10^{-9}$ & $1.26 \times 10^{-10}$ & $2.68 \times 10^{-29}$ & $2.67 \times 10^{-29}$ \\
\hline 600 & $9.44 \times 10^{-17}$ & $1.99 \times 10^{16}$ & $2.06 \times 10^{85}$ & $5.31 \times 10^{-4}$ & $2.21 \times 10^{-5}$ & $7.95 \times 10^{-7}$ & $6.72 \times 10^{-22}$ & $6.69 \times 10^{-22}$ \\
\hline 700 & $1.93 \times 10^{-13}$ & $3.99 \times 10^{13}$ & $1.56 \times 10^{74}$ & 0.13 & $7.23 \times 10^{-3}$ & $4.20 \times 10^{-4}$ & $1.34 \times 10^{-16}$ & $1.33 \times 10^{-16}$ \\
\hline 800 & $5.79 \times 10^{-11}$ & $1.18 \times 10^{10}$ & $6.96 \times 10^{65}$ & 8.45 & 0.56 & $4.69 \times 10^{-2}$ & $1.28 \times 10^{-12}$ & $1.28 \times 10^{-12}$ \\
\hline 900 & $4.81 \times 10^{-9}$ & $9.81 \times 10^{9}$ & $2.20 \times 10^{59}$ & 217.07 & 16.81 & 1.86 & $1.62 \times 10^{-9}$ & $1.61 \times 10^{-9}$ \\
\hline 1000 & $1.63 \times 10^{-7}$ & $3.33 \times 10^{7}$ & $1.36 \times 10^{54}$ & $2.95 \times 10^{3}$ & 256.29 & 35.40 & $4.95 \times 10^{-7}$ & $4.93 \times 10^{-7}$ \\
\hline 1200 & $3.12 \times 10^{-5}$ & $6.41 \times 10^{5}$ & $2.03 \times 10^{46}$ & $1.50 \times 10^{5}$ & $1.54 \times 10^{4}$ & $2.99 \times 10^{3}$ & $2.67 \times 10^{-3}$ & $2.66 \times 10^{-3}$ \\
\hline 1400 & $1.28 \times 10^{-3}$ & $2.67 \times 10^{3}$ & $5.00 \times 10^{40}$ & $2.54 \times 10^{6}$ & $2.91 \times 10^{5}$ & $7.17 \times 10^{4}$ & 1.25 & 1.25 \\
\hline 1600 & $2.03 \times 10^{-2}$ & $4.27 \times 10^{2}$ & $3.02 \times 10^{36}$ & $2.14 \times 10^{7}$ & $2.65 \times 10^{6}$ & $7.83 \times 10^{5}$ & 126.54 & $126.09 \times 10^{3}$ \\
\hline 1800 & 0.17 & 872.9 & $1.54 \times 10^{33}$ & $1.14 \times 10^{8}$ & $1.48 \times 10^{7}$ & $5.05 \times 10^{6}$ & $5.05 \times 10^{3}$ & $4.59 \times 10^{3}$ \\
\hline 2000 & 0.92 & 0.36 & $3.51 \times 10^{30}$ & $4.33 \times 10^{8}$ & $5.90 \times 10^{7}$ & $2.25 \times 10^{7}$ & $8.195 \times 10^{4}$ & $8.16 \times 10^{4}$ \\
\hline
\end{tabular}

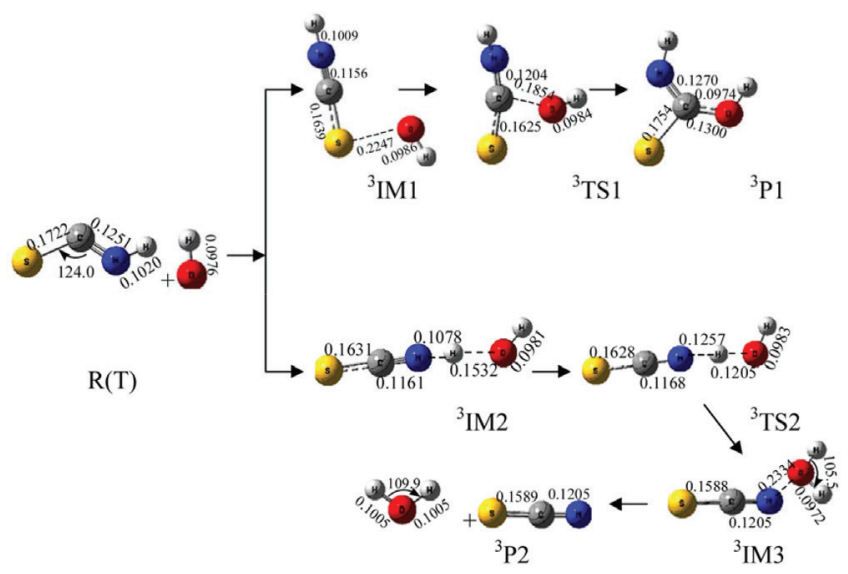

Figure 3. Optimized geometries of various species in reaction in triplet state (bond lengths in $\mathrm{nm}$ and bond angles in degree)

of $\mathrm{H} 1-\mathrm{O}$ bond varied from $0.1532 \mathrm{~nm}\left({ }^{3} \mathrm{IM} 2\right)$ to $0.1185 \mathrm{~nm}\left({ }^{3} \mathrm{TS} 2\right)$ to $0.0972 \mathrm{~nm}$ ( $\left.{ }^{3} \mathrm{IM} 3\right)$. In this step, H1-O bond formed and H1-N bond dissociated gradually. The formation of ${ }^{3} \mathrm{IM} 3$ from ${ }^{3} \mathrm{IM} 2$ through transition state ${ }^{3} \mathrm{TS} 2$ had the energy barrier of $309.5 \mathrm{~kJ} \mathrm{~mol}^{-1}$. Finally, ${ }^{3} \mathrm{IM} 3$ dissociated into generate product ${ }^{3} \mathrm{P} 2\left({ }^{3} \mathrm{SCN}^{-}+\mathrm{H}_{2} \mathrm{O}\right)$.

Comparing the two pathways, the direct extraction $\mathrm{OH}^{-}$channel had the lowest energy barrier. Therefore, the direct extraction $\mathrm{OH}^{-}$ channel was the major reaction channel in the reaction of triplet state $\mathrm{OH}^{-}$with $\mathrm{HNCS}$.

\section{CONCLUSIONS}

In this study, the B3LYP method of density functional theory was employed to research the reaction mechanism of $\mathrm{OH}^{-}$and HNCS. The calculation results showed that the reaction of singlet state had four feasible pathways and that of triplet state was two. The H1atom in $\mathrm{HNCS}$ transfer to $\mathrm{OH}^{-}$channel in singlet state reaction was the main reaction channel with the lowest energy barrier. The rate constant and equilibrium constant of the H1-atom in HNCS transfer

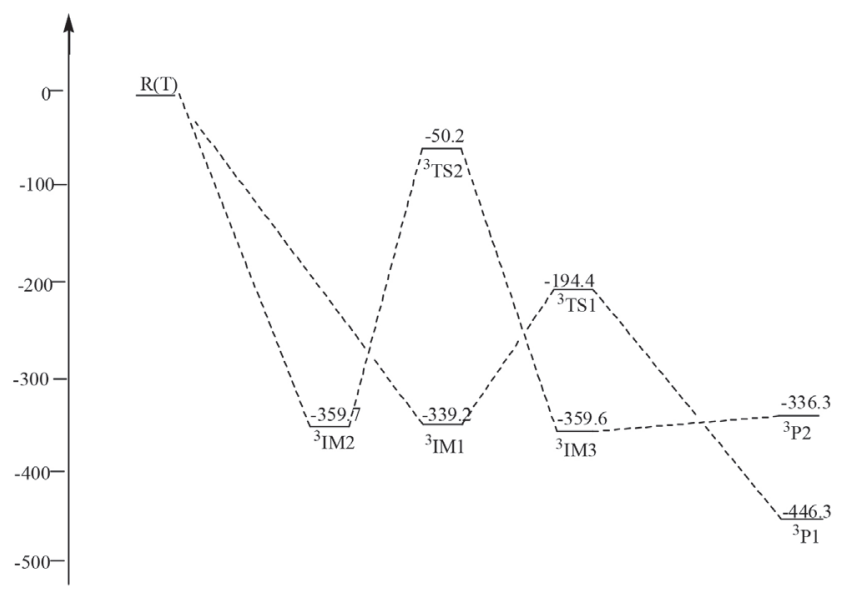

Figure 4. Schematic map of energy levels in triplet state (relative energies in $\mathrm{kJ} \mathrm{mol}^{-1}$ )

to $\mathrm{OH}^{-}$channel in singlet state were higher than other channels in the temperature range of 100 to $2000 \mathrm{~K}$. This study might provide theoretical clue to control environment pollution. By comparing with the main channel of singlet state reaction, the energy barrier of this pathway was higher. So, the reaction of triplet state was not the predominant way of $\mathrm{OH}^{-}$with $\mathrm{HNCS}$ reaction.

\section{SUPPLEMENTARY MATERIAL}

A table with the energies, relative energies and frequencies of the reaction can be found at http://quimicanova.sbq.org.br in pdf format, with free access.

\section{ACKNOWLEDGMENTS}

This work was supported by the Scientific Research Project of Gansu Province Higher Education (No.2016B-098) and the Applied Chemistry Key Subject of Gansu Province (No. GSACKS20130113). 


\section{REFERENCES}

1. Northrup, F. J.; Sears T. J.; Chem. Phys. Lett. 1989, 159, 421.

2. Baren, R. E.; Hershberger, J. F.; J. Phys. Chem. A 1999, 103, 11340.

3. Perry, R. A.; Siebers, D. L.; Nature 1986, 324, 657.

4. Miller, J. A.; Bowman, C. T.; Prog. Energy Combust. Sci. 1989, 15, 287.

5. Miller, J. A.; Bowman, C. T.; Int. J. Chem. Kinet. 1991, 23, 289.

6. Brown, S. S.; Berghot, H. L.; Crim, F. F.; J. Phys. Chem. A 1996, 100, 7948.

7. McDonald, J. R.; Scherr, V. M.; McGlynn, S. P.; J. Chem. Phys. 1969, $51,1723$.

8. Wierzejewska, M.; Wieczorek, R.; J. Chem. Phys. 2003, 287, 169.

9. Wierzejewska, M.; Olbert-Majkut, A.; J. Phys. Chem. A. 2003, 107, 1928.

10. Hou, L. J.; Kong, C.; Han, Y. X.; Chen, D. P.; Gao, L. G.; J. At. Mol. Phys. 2012, 29, 988.

11. Kong, C.; Han, Y. X.; Chen, D. P.; J. At. Mol. Phys. 2011, $28,823$.

12. Hou, L. J.; Kong, C.; Han, Y. X.; Chen, D. P.; Gao, L. G.; J. At. Mol. Phys. 2013, 30, 707.

13. Li-Jie, H.; Bo-Wan, W.; Yan-Xia, H.; Comput. Theor. Chem. 2015, 1051, 57.

14. Liu, P. J.; Zhao, M.; Pan, X. M.; Acta Chim. Sin. 2004, 62, 1991.

15. Liu, P. J.; Du, Q. S.; Chang, Y. F.; Acta Phys.-Chim. Sin. 2005, 12, 1347.

16. Liu, P. J.; Zhang, L. H.; Sun, H.; Chang, Y. F.; Wang, R. S.; Chem. Res. Chin. Univ. 2006, 22, 635.

17. Xu, B. H.; Li, L. C.; Zhu, Y. Q.; Acta Sci. Nat. Univ. Szechuan. 2007, 44, 653.

18. Han, Y. X.; Gang, Z. Y.; Wang, Y. C.; Liang, J. X.; Yan, P. J.; Acta Chim. Sin. 2009, 67, 773.

19. Cuihong, S.; Ying, L.; Baoen, X.; Zeng, Y.; Meng, L.; Zhang, S.; J. Chem. Phys. 2013, 139, 154307-1.

20. Wayne, R. P.; Chemistry of Atmospheres, $2^{\text {nd }}$ ed., Clarendon Press: Oxford, 1991.
21. Anglada, J. M.; J. Phys. Chem. A 2005, 109, 10786.

22. Alvarez-Idaboy, J. R.; Mora-Diez, N.; Boyd, R. J.; Vivier-Bunge, A.; J. Am. Chem. Soc. 2001, 123, 2018.

23. Aloisio, S.; Francisco, J. S.; J. Phys. Chem. A 2000, 104, 3211.

24. Takahashi, H.; Hori, T.; Wakabayashi, T.; Nitta, T.; J. Phys. Chem. A 2001, 105, 4351.

25. Li, H.-Y.; Pu, M.; Ji, Y.-Q.; Xu, Z.-F.; Feng, W.-L.; J. Chem. Phys. 2004, $307,35$.

26. Madura, J. D; Jorgensen, W. L.; J .Am .Chem .Soc. 1986, 108, 2517.

27. Frisch, M. J.; Trucks, G. W.; Schlegel, H. B.; Scuseria, G. E.; Robb, M. A.; Cheeseman, J. R.; Montgomery, Jr., J. A.; Vreven, T.; Kudin, K. N.; Burant, J. C.; Millam, J. M.; Iyengar, S. S.; Tomasi, J.; Barone, V.; Mennucci, B.; Cossi, M.; Scalmani, G.; Rega, N.; Petersson, G. A.; Nakatsuji, H.; Hada, M.; Ehara, M.; Toyota, K.; Fukuda, R.; Hasegawa, J.; Ishida, M.; Nakajima, T.; Honda, Y.; Kitao, O.; Nakai, H.; Klene, M.; Li, X.; Knox, J. E.; Hratchian, H. P.; Cross, J. B.; Bakken, V.; Adamo, C.; Jaramillo, J.; Gomperts, R.; Stratmann, R. E.; Yazyev, O.; Austin, A. J.; Cammi, R.; Pomelli, C.; Ochterski, J. W.; Ayala, P. Y.; Morokuma, K.; Voth, G. A.; Salvador, P.; Dannenberg, J. J.; Zakrzewski, V. G.; Dapprich, S.; Daniels, A. D.; Strain, M. C.; Farkas, O.; Malick, D. K.; Rabuck, A. D.; Raghavachari, K.; Foresman, J. B.; Ortiz, J. V.; Cui, Q.; Baboul, A. G.; Clifford, S.; Cioslowski, J.; Stefanov, B. B.; Liu, G.; Liashenko, A.; Piskorz, P.; Komaromi, I.; Martin, R. L.; Fox, D. J.; Keith, T.; Al-Laham, M. A.; Peng, C. Y.; Nanayakkara, A.; Challacombe, M.; Gill, P. M. W.; Johnson, B.; Chen, W.; Wong, M. W.; Gonzalez, C.; Pople, J. A.; Gaussian 03, Revision B.01, Gaussian, Inc., Wallingford CT, 2004.

28. Su, M. D.; Chu, S. Y.; J. Am. Chem. Soc. 1999, 121, 4229.

29. Becke, A. D.; Kohn, W.; Parr, R. G.; J. Phys. Chem. 1996, 100, 12974.

30. Becke, A. D.; Phys. Rev. A 1988, 38, 3098.

31. Fukui, K. A.; J. Phys. Chem. 1970, 74, 4161.

32. Reed, A. E.; Curtiss, L. A.; Weinhold, F.; Chem. Rev. 1988, 88, 899. 